\title{
Experimental and theoretical assessing the salts effect on the equilibrium of water + acetone + $\mathrm{HMIMPF}_{6}$ ionic liquid system
}

\author{
Javad Saien $^{\mathrm{a}, *}$, Marjan Mohammadi Sarab Badieh ${ }^{\mathrm{a}}$, Mahdi Norouzi ${ }^{\mathrm{b}}$ \\ ${ }^{a}$ Department of Applied Chemistry, Bu-Ali Sina University, Hamedan 65174, Iran \\ ${ }^{\mathrm{b}}$ Department of Chemical and Chemical Engineering, Malek-Ashtar University of Technology, 3454, Tehran, Iran
}

\begin{abstract}
The influence of naturally occurring monovalent $\mathrm{NaCl}$ and divalent $\mathrm{Na}_{2} \mathrm{SO}_{4}$ salts with anions at near extremes of Hafmester series on liquid-liquid equilibrium (LLE) of the chemical system of $\left\{\right.$ water + acetone + 1-Hexyl-3-methylimidazolium hexafluorophosphate $\left(\mathrm{HMIMPF}_{6}\right)$ ionic liquid\} was studied. The conditions were $298.2 \mathrm{~K}$, atmospheric pressure of $81.5 \mathrm{kPa}$ and salts mass fractions in initial aqueous solutions of 0.05 and 0.10 . Results show that salting-out effect was significant, so that enhancements in the acetone distribution coefficient was achieved within (21.67 to 35.54$) \%$ for $\mathrm{NaCl}$ and (51.84 to 92.37$) \%$ for $\mathrm{Na}_{2} \mathrm{SO}_{4}$. The stronger anion activity and the lack of anion exchange with the used ionic liquid can be the reasons for the stronger effect of the latter salt. The consistency of the experimental data were examined with the improved EisenJoffe equation. For modeling purpose, The NRTL and UNIQUAC equations were satisfactorily applied to correlate the phase equilibria. In the presence of $\mathrm{NaCl}$ and $\mathrm{Na}_{2} \mathrm{SO}_{4}$ salts, the root mean square deviations of compositions, for NRTL equation were 0.0346 and 0.0634 and for UNIQUAC equation 0.1093 and 0.0328 , respectively.
\end{abstract}

Keywords: Ionic liquids; Salt effect; Experimental LLE; Separation factor; LLE correlation

\section{Introduction}

Room temperature ionic liquids (RTILs or ILs) are considered to be environmentally friendlier than common organic solvents and have unique chemical and physical properties such as negligible vapor pressure, non-flammability, thermal stability, in addition to tunable viscosity and miscibility with water and organic solvents [1,2]. The application of ILs as green solvents instead of organic solvents has therefore attracted considerable attention in the field of separation

*Corresponding author. Tel. and Fax: +98 8138282807.

E-mail address: saien@basu.ac.ir (J. Saien). 
and purification processes. Accordingly, liquid-liquid extraction is a process with specific applications in many areas of separation and purification and its performance depends on the action of the solvent $[3,4]$. One major requirement in evaluating the performance of this process is the system equilibrium conditions.

Water sources, conventionally used in industry, contain salts at different levels and the presence of salts can significantly change the liquid-liquid equilibrium (LLE) condition of pure chemical systems. Currently, the LLE of ternary systems, containing ILs and organic molecules $[2,5-7]$, as well as the electrolytes in their role the shifting the equilibrium tie-lines is being studied $[2,8]$. LLE is the result of molecular interactions, which can significantly change due to presence of salts, which causes ionic forces, affecting the thermodynamic equilibrium [9].

The corresponding phenomena, known as "salting-out effect", cause the distribution of an organic solute between organic and aqueous phases to enrich more the organic phase relative to aqueous phase. This matter can be explained by hydrating of salt ions where some of the water molecules surrounding electrolyte molecules become unavailable; therefore, the solute tendency is favored to transfer more from aqueous phase to organic phase [8-11].

One major problem in LLE is accurately measurement of compositions in each phase. Two major methodologies are usually employed in this regard. The first method benefits the direct analysis where the components are well mixed and allowed to separate into liquid phases. Then the composition of each phase is determined by direct analyzing of the components. The second method involves two separate steps. First, a relationship between the compositions and a property (density or refractive index) is established from the known composition of immediate and stable cloud solutions. In this regard, "cloud-point with refractive index measurement" is a method that has been extensively employed [12-15]. The method gives binodal points or solubility curve. Whenever this relationship is provided, measuring the refractive index in each phase would be adequate to determine a tie line.

Recently, we studied the LLE of "water + acetone + $\mathrm{HMIMPF}_{6}$ ionic liquid" system [16]. The high capability of this IL, as a green solvent for extraction of acetone from aqueous solutions, was explored. Acetone and water components have been involved in one standard chemical test system, recommended by the European Federation of Chemical Engineers (EFCE) for liquid-liquid extraction studies [17]. 
Considering the inevitable presence of electrolytes and their important role in altering the LLE of pure chemical systems, the influence of two conventional water present salts, monovalent $(\mathrm{NaCl})$ and divalent $\left(\mathrm{Na}_{2} \mathrm{SO}_{4}\right)$ with anions from the Hafmester series, on the considered liquid-liquid system was investigated here. The two steps cloud point measurement method was employed in the experiments. Accordingly, distribution coefficients and separation factors were obtained. For modeling, the well-known NRTL and UNIQUAC thermodynamic models were employed and the interaction parameters were determined using Aspen Plus simulator.

\section{Experimental}

\subsection{Chemicals}

1-methylimidazole, 1-chlorohexane, ethyl acetate (raw materials for the IL synthesis), acetone, sodium chloride and sodium sulphate were purchased from Merck. Hexafluorophosphate acid $\left(\mathrm{HPF}_{6}\right)$ was obtained from Acros Organics. The chemicals were used without further purification. In Table 1 is summarized the provenance and mass fraction purity of the materials used in this work. Fresh deionized water was generated from a deionizer apparatus (Hastaran Co.), producing water with electrical conductivity of less than $0.08 \mu \mathrm{S} . \mathrm{cm}^{-1}$.

Ionic liquid of $\mathrm{HMIMPF}_{6}$ was prepared according to the previous literature procedure [10]. Fig. 1 shows the $\mathrm{HMIMPF}_{6}$ structure.

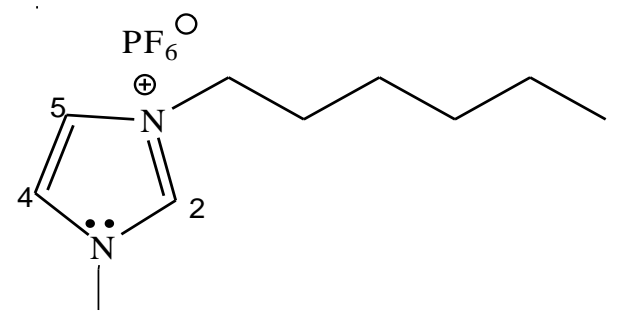

Fig. 1. The chemical structure of $\mathrm{HMIMPF}_{6}$. 


\section{Table 1}

Supplier and mass fraction purity of the used materials.

\begin{tabular}{lll}
\hline Chemical & Supplier & Mass fraction purity \\
\hline Acetone & Merck & 0.999 \\
1-methylimidazole & Merck & 0.99 \\
1-chlorohexane & Merck & 0.99 \\
ethyl acetate & Merck & 0.995 \\
hexafluorophosphate acid & Acros Organics & 0.60 \\
Sodium chloride & Merck & $\geq 0.998$ \\
Sodium sulphate & Merck & $\geq 0.99$ \\
HMIMPF $_{6}$ & synthesized & 0.99 \\
\hline
\end{tabular}

" informed by the suppliers except for $\mathrm{HMIMPF}_{6}$ that was determined by standard chloride titration method.

Given in Table 2 are density $(\rho)$ and refractive index $\left(n_{d}\right)$ of the used components in comparison with the literature reported values. Densities were measured by means of an oscillating U-tube densimeter (Anton Paar DMA4500, Austria) with an uncertainty of \pm 0.00001 g. $\mathrm{cm}^{-3}$, provided with automatic viscosity correction and refractive indexes were determined with an Abbe refractometer (AR4, Kruss, Germany) having an accuracy of 0.00005. Also, samples were weighted with an electronic Ohaus balance, Adventurer, Pro AV264, Switzerland, $\pm 0.00001 \mathrm{~g} . \mathrm{cm}^{-3}$ and the temperature examined by means of an accurate thermometer, Amadigit, ad 3000th, Percica, Germany.

\section{Table 2}

Density $(\rho)$ and refractive index $\left(n_{d}\right)$ of the components, compared with literature at temperature of $298.2 \mathrm{~K}$ and under atmospheric pressure of $81.5 \mathrm{kPa}{ }^{*}$

\begin{tabular}{lccccc}
\hline \multirow{2}{*}{ Component } & \multicolumn{2}{c}{$\rho\left({\left.\mathrm{g} . \mathrm{cm}^{-3}\right)}\right.$} & & \multicolumn{2}{c}{$n_{d}$} \\
\cline { 2 - 3 } \cline { 5 - 6 } & Exp. & Lit. & & Exp. & Lit. \\
\hline HMIMPF $_{6}$ & 1.29088 & $1.2937[18]$ & & 1.41640 & $1.41787[18]$ \\
Acetone & 0.78440 & $0.7845[19]$ & & 1.35575 & $1.35566[18]$ \\
Water & 0.99704 & $0.99693[19]$ & & 1.33250 & $1.33250[20]$
\end{tabular}

${ }^{\circ}$ Standard average uncertainties are $u\left(n_{d}\right)= \pm 0.00005, u(T)= \pm 0.1 \mathrm{~K}, u(\rho)= \pm 0.00001 \mathrm{~g} . \mathrm{cm}^{-3}$ and $u(p)= \pm 0.3 \mathrm{kPa}$.

\subsection{Apparatus and procedure}

The solubility of components was characterized by the cloud-point with refractive index measurement using a thermostated miniature cell with about $5 \mathrm{~cm}^{3}$ volume, equipped with a 
magnetic stirrer and isothermal fluid jacketed. The temperature was held constant by circulating water from a water bath (Julabo, Germany) through the jacket of the cell, and with temperature uncertainty of $\pm 0.1 \mathrm{~K}$. All experiments were performed at constant temperature of $298.2 \mathrm{~K}$ and under atmospheric pressure of $81.5 \pm 0.3 \mathrm{kPa}$.

Binary mixtures of (aqueous salt solution + acetone) or $\left(\mathrm{HMIMPF}_{6}+\right.$ acetone) with known compositions were introduced to the cell and stirred at constant temperature. The corresponding third component (HMIMPF 6 or aqueous salt solution) was titrated into the cell from a microburet with an uncertainty of $\pm 0.1 \mathrm{~mm}^{3}$. The end point was detected by observing the transition from a homogeneous to a heterogeneous cloud mixture. The amount of each of used components (water, acetone, $\mathrm{HMIMPF}_{6}$ as well as salt) was therefore known for cloud point detection of solutions. Then, it was allowed to rest $1 \mathrm{~h}$ for phase splitting, and 3 samples of the solution bulk were taken. The refractive index of samples was then measured and the average value was considered. Also, temperature of the refractometer was retained constant at the same temperature of mixtures (298.2 K) by circulating water from the water bath. The perfect samples composition and the refractive indexes for this part of work are given as Tables S-1-3 in the supplementary information.

The mass fraction of salts in aqueous solution was 0.05 and 0.10 ; these concentrations are much below the saturation in water at temperature of $298.2 \mathrm{~K}$. In the case of using $\mathrm{Na}_{2} \mathrm{SO}_{4}$, precipitation of the salt happens at high level concentrations of acetone. Addition of acetone, a component with much capable of hydrogen-bonding with water, reduces the amount of available water molecules needed for solving the salt ions. Thus, one can look at this situation as excess concentration of the salt and, likewise, causes precipitation of the salt.

The precipitation of salts, during the solubility curve determination, is a major difficulty in the experiments with salt containing liquid mixtures which would mask the disappearance of turbidity during titrations. This matter has been reported In several investigations [12,21,22]. For this reason we employed a relatively low salts mass fraction of 0.05 and 0.10 , equivalent to 0.35 and 0.70 mol. $\mathrm{L}^{-1}$ molar concentrations of $\mathrm{Na}_{2} \mathrm{SO}_{4}$ and 0.9 and $1.7 \mathrm{~mol} . \mathrm{L}^{-1}$ of $\mathrm{NaCl}$ (all based on initial water content).

Figs. 2-4 show dependency of refractive index on the compositions of cloudy solutions at $298.2 \mathrm{~K}$. Generally, $w_{i 1}$ and $w_{i 3}$ refer to the mass fractions of the $i$ th (water $=1$, acetone $=2$, $\mathrm{HMIMPF}_{6}=3$ and salt $\left.=4\right)$ component in the aqueous and the IL phases, respectively. Results 
show that in cloudy samples, refractive index of aqueous phase is increased with incrementing the added acetone due to higher refractive index of acetone, compared to water. It is while, a contrary variation is observed in the IL phase due to lower refractive index of acetone compared to $\mathrm{HMIMPF}_{6}$. Similar explanation can be given for variation of refractive index when water is added to the samples. It is also obvious that salts (with the used concentations) provide no significant shift on the refractive index curves in the IL solutions, which is due to low solubility of salts in the IL solutions [23].

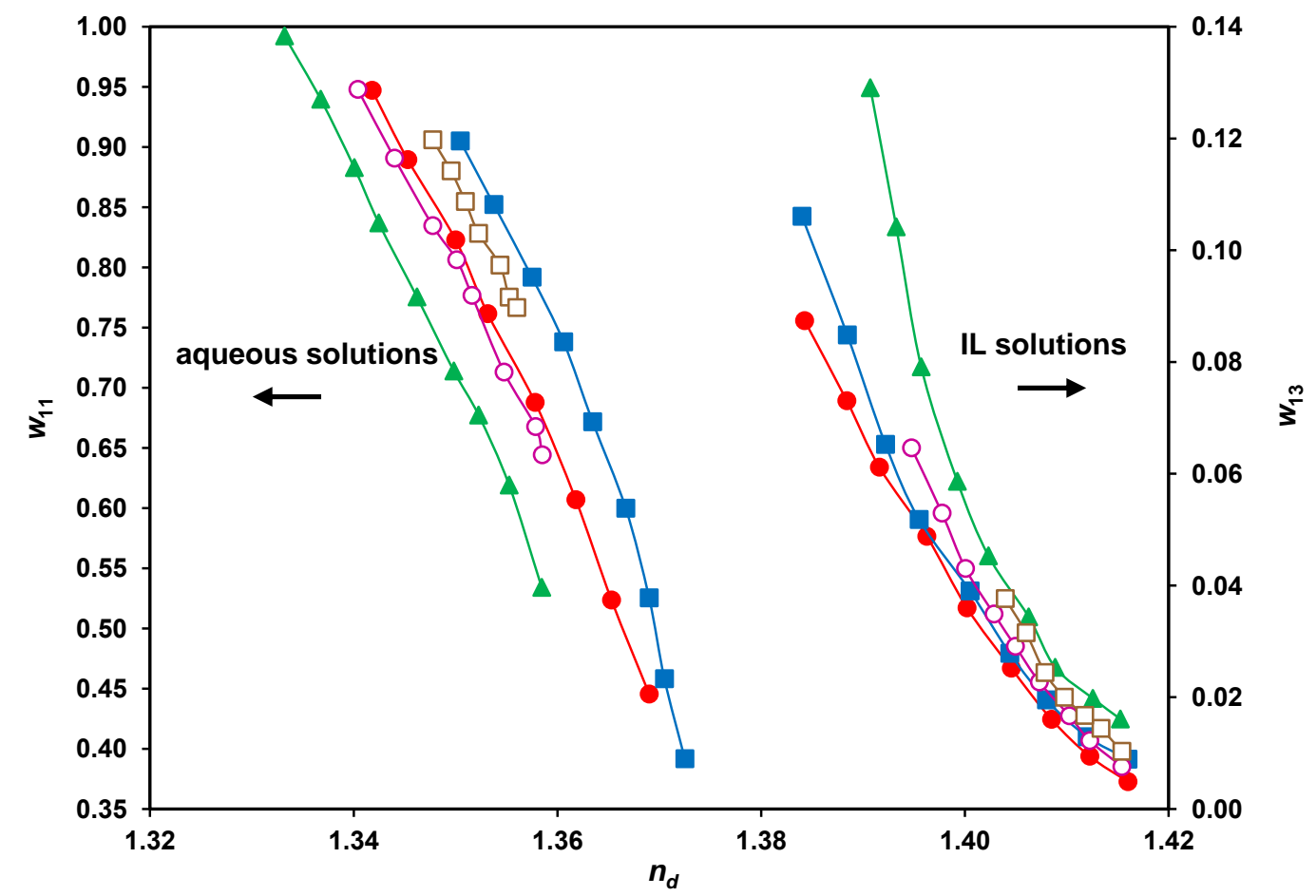

Fig. 2. Dependency of water compositions on the refractive index of cloudy solutions: salt-free $(\boldsymbol{\Delta}), 0.05(\bullet)$ and $0.10(\mathbf{\square})$ mass fractions of $\mathrm{NaCl}$, and $0.05(\circ)$ and $0.10(\square)$ mass fractions of $\mathrm{Na}_{2} \mathrm{SO}_{4}$; for aqueous and IL solutions. 


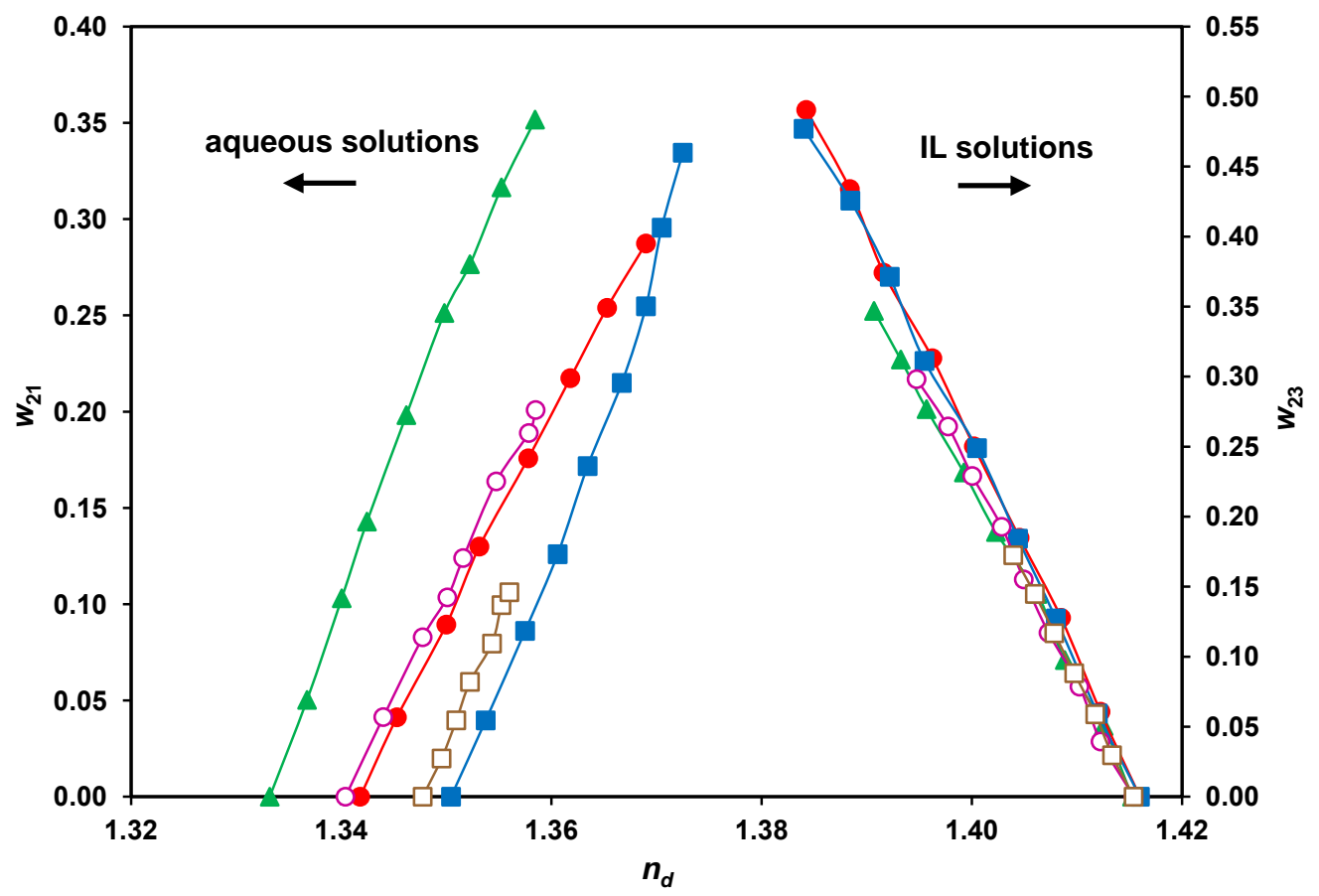

Fig. 3. Dependency of acetone compositions on the refractive index of cloudy solutions: salt-free $(\boldsymbol{\Delta}), 0.05(\bullet)$ and $0.10(\square)$ mass fractions of $\mathrm{NaCl}$, and $0.05(\circ)$ and $0.10(\square)$ mass fractions of $\mathrm{Na}_{2} \mathrm{SO}_{4}$; for aqueous and IL solutions.

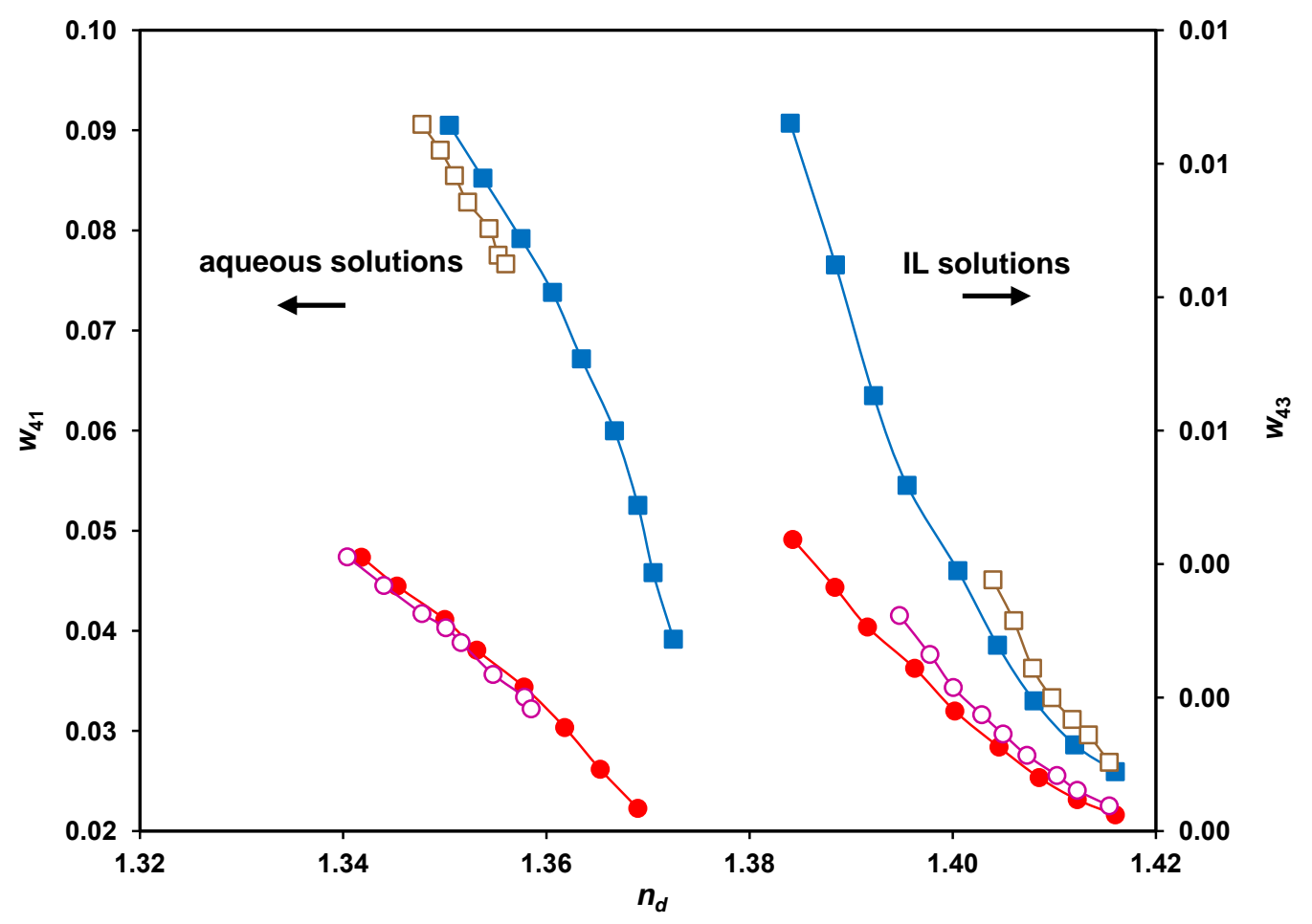

Fig. 4. Dependency of salt compositions on the refractive index of cloudy solutions: salt-free $(\mathbf{\Delta}), 0.05(\bullet)$ and 0.10 (-) mass fractions of $\mathrm{NaCl}$, and $0.05(\circ)$ and $0.10(\square)$ mass fractions of $\mathrm{Na}_{2} \mathrm{SO}_{4}$; for aqueous and IL solutions. 
To obtain the tie line data, a tightly closed miniature equilibrium cell with about $5 \mathrm{~cm}^{3}$ volume was used. Mixtures of known masses of the components were transfered into the cell, and located in a shaker water bath (N-BIOTEK-304) and temperature adjusted with uncertainty of $\pm 0.1 \mathrm{~K}$. Content of each cell was shaking for $4 \mathrm{~h}$ at $175 \mathrm{rpm}$ and then allowed to rest $12 \mathrm{~h}$ for settling layers, all at temperature of $298.2 \mathrm{~K}$. To determine each equilibrium phase composition, samples were withdrawn from each phase carefully and analyzed via measuring the refractive index. Once the calibration curves were constructed, the compositions of the unknown mixtures (corresponding to tie lines) were obtained with an estimated maximum uncertainty of \pm 0.0005 in mass fraction. Similar procedure for determination of composition of tie lines has been used by other investigators [24-26].

\section{Results and discussion}

\subsection{Tie-line data}

The experimental tie line data for the ternary water (1) + acetone (2) $+\mathrm{HMIMPF}_{6}$ (3) system without salt and in the presence of $\mathrm{NaCl}$ and $\mathrm{Na}_{2} \mathrm{SO}_{4}$ salts (4) are presented in Table 3. The distribution coefficients of water $\left(D_{1}\right)$ and of acetone $\left(D_{2}\right)$, given in this table, are defined as:

$$
\begin{aligned}
& D_{1}=\frac{w_{13}}{w_{11}} \\
& D_{2}=\frac{w_{23}}{w_{21}}
\end{aligned}
$$

Another criterion of the extraction effectiveness is separation factor $(S)$ which is here an indication of the relative amount of acetone in the IL to aqueous phases. It is given as:

$$
S=\frac{D_{2}}{D_{1}}
$$

\section{Table 3}

\begin{tabular}{|c|c|c|c|c|c|c|c|}
\hline \multicolumn{4}{|c|}{ Water-rich phase } & \multicolumn{4}{|c|}{ HMIMPF $_{6}$-rich phase } \\
\hline$w_{11}$ & $w_{21}$ & $w_{31}$ & $w_{41}$ & $w_{13}$ & $w_{23}$ & $w_{33}$ & $w_{43}$ \\
\hline \multicolumn{8}{|c|}{ Salt-free } \\
\hline 0.9244 & 0.0673 & 0.0083 & & 0.0199 & 0.0648 & 0.9153 & \\
\hline 0.8771 & 0.1133 & 0.0096 & & 0.0260 & 0.1149 & 0.8591 & \\
\hline
\end{tabular}

Experimental tie-line data (in mass fraction) for the ternary water (1) + acetone (2) $+\mathrm{HMIMPF}_{6}(3)$ system, salt-free and with $\mathrm{NaCl}$ or $\mathrm{Na}_{2} \mathrm{SO}_{4}$ salts at temperature of $298.2 \mathrm{~K}$ and ambinet pressure of $81.5 \mathrm{kPa}$.* 


\begin{tabular}{|c|c|c|c|c|c|c|c|}
\hline 0.8311 & 0.1546 & 0.0143 & & 0.0367 & 0.1639 & 0.7994 & \\
\hline 0.7745 & 0.2012 & 0.0243 & & 0.0557 & 0.2202 & 0.7241 & \\
\hline 0.7365 & 0.2302 & 0.0333 & & 0.0712 & 0.2549 & 0.6739 & \\
\hline 0.7236 & 0.2397 & 0.0367 & & 0.0768 & 0.2661 & 0.6571 & \\
\hline 0.6536 & 0.2878 & 0.0586 & & 0.1128 & 0.3259 & 0.5613 & \\
\hline 0.5641 & 0.3424 & 0.0935 & & 0.1676 & 0.3945 & 0.4379 & \\
\hline \multicolumn{8}{|c|}{$0.05 \mathrm{NaCl}$} \\
\hline 0.8597 & 0.0914 & 0.0057 & 0.0432 & 0.0163 & 0.1206 & 0.8623 & 0.0008 \\
\hline 0.8192 & 0.1305 & 0.0092 & 0.0411 & 0.0240 & 0.1773 & 0.7974 & 0.0012 \\
\hline 0.7720 & 0.1726 & 0.0166 & 0.0388 & 0.0349 & 0.2464 & 0.7169 & 0.0018 \\
\hline 0.6924 & 0.2370 & 0.0358 & 0.0348 & 0.0553 & 0.3543 & 0.5876 & 0.0028 \\
\hline 0.6190 & 0.2903 & 0.0596 & 0.0311 & 0.0763 & 0.4462 & 0.4737 & 0.0038 \\
\hline 0.5449 & 0.3394 & 0.0883 & 0.0274 & 0.0984 & 0.5294 & 0.3673 & 0.0049 \\
\hline 0.4968 & 0.3691 & 0.1091 & 0.0250 & 0.1122 & 0.5764 & 0.3058 & 0.0056 \\
\hline \multicolumn{8}{|c|}{$0.10 \mathrm{NaCl}$} \\
\hline 0.8514 & 0.0596 & 0.0039 & 0.0851 & 0.0161 & 0.0670 & 0.9155 & 0.0014 \\
\hline 0.7748 & 0.1383 & 0.0094 & 0.0775 & 0.0276 & 0.1695 & 0.8004 & 0.0025 \\
\hline 0.7390 & 0.1719 & 0.0152 & 0.0739 & 0.0362 & 0.2229 & 0.7375 & 0.0034 \\
\hline 0.6876 & 0.2180 & 0.0257 & 0.0687 & 0.0519 & 0.2982 & 0.6450 & 0.0049 \\
\hline 0.6096 & 0.2846 & 0.0448 & 0.0610 & 0.0856 & 0.4167 & 0.4894 & 0.0083 \\
\hline 0.5440 & 0.3384 & 0.0632 & 0.0544 & 0.1181 & 0.5023 & 0.3680 & 0.0116 \\
\hline 0.4724 & 0.3955 & 0.0849 & 0.0472 & 0.1558 & 0.5826 & 0.2463 & 0.0153 \\
\hline 0.4124 & 0.4423 & 0.1041 & 0.0412 & 0.1760 & 0.6200 & 0.1866 & 0.0174 \\
\hline \multicolumn{8}{|c|}{$0.05 \mathrm{Na}_{2} \mathrm{SO}_{4}$} \\
\hline 0.9041 & 0.0383 & 0.0117 & 0.0459 & 0.0135 & 0.0566 & 0.9289 & 0.0010 \\
\hline 0.8735 & 0.0703 & 0.0118 & 0.0444 & 0.0203 & 0.1081 & 0.8702 & 0.0014 \\
\hline 0.8484 & 0.0955 & 0.0130 & 0.0431 & 0.0276 & 0.1518 & 0.8189 & 0.0017 \\
\hline 0.8176 & 0.1251 & 0.0157 & 0.0416 & 0.0387 & 0.2068 & 0.7522 & 0.0023 \\
\hline 0.7839 & 0.1561 & 0.0201 & 0.0399 & 0.0529 & 0.2637 & 0.6804 & 0.0030 \\
\hline 0.7454 & 0.1900 & 0.0265 & 0.0381 & 0.0720 & 0.3270 & 0.5971 & 0.0039 \\
\hline 0.7205 & 0.2111 & 0.0315 & 0.0369 & 0.0858 & 0.3664 & 0.5432 & 0.0046 \\
\hline 0.6803 & 0.2441 & 0.0407 & 0.0349 & 0.1104 & 0.4271 & 0.4566 & 0.0059 \\
\hline \multicolumn{8}{|c|}{$0.10 \mathrm{Na}_{2} \mathrm{SO}_{4}$} \\
\hline 0.8676 & 0.0403 & 0.0053 & 0.0868 & 0.0133 & 0.0804 & 0.9042 & 0.0021 \\
\hline 0.8593 & 0.0491 & 0.0057 & 0.0859 & 0.0160 & 0.0987 & 0.8829 & 0.0024 \\
\hline 0.8467 & 0.0623 & 0.0063 & 0.0847 & 0.0213 & 0.1285 & 0.8473 & 0.0029 \\
\hline 0.8236 & 0.0865 & 0.0076 & 0.0823 & 0.0341 & 0.1843 & 0.7774 & 0.0042 \\
\hline 0.8062 & 0.1046 & 0.0086 & 0.0806 & 0.0469 & 0.2270 & 0.7206 & 0.0055 \\
\hline 0.7982 & 0.1129 & 0.0091 & 0.0798 & 0.0540 & 0.2472 & 0.6926 & 0.0062 \\
\hline 0.7812 & 0.1305 & 0.0102 & 0.0781 & 0.0712 & 0.2892 & 0.6317 & 0.0079 \\
\hline
\end{tabular}

*Standard average uncertainties are $u\left(n_{d}\right)= \pm 0.00005, u(T)= \pm 0.1 \mathrm{~K}, u(p)= \pm 0.3 \mathrm{kPa}$ and $u(w)=$ \pm 0.0005 .

Data for salt-free system show that for the most tie-lines, acetone is more soluble in the IL phase which can be due to hydrogen bonding between acetone and the IL [16]. Indeed, because 
of salting-out effect, the solubility of acetone in aqueous phase decreases in the presence of salts and therefore its extraction by the IL is significantly improved [10].

Fig. 5 shows variation of acetone distribution coefficient $\left(D_{2}\right)$ as a function of its concentration in aqueous phase. The diagram demonstrates that higher distribution coefficients are relevant to higher acetone concentration even in salt-free solutions. Adding 0.05 mass fraction of $\mathrm{NaCl}$ to the samples leads to an average enhancement of about $35.54 \%$ in distribution coefficient, and hence, it decreases to about $21.67 \%$ by adding 0.10 mass fraction of this salt due to most probable anion exchange between $\mathrm{NaCl}$ and the IL. It is worth noting that using high concentration of $\mathrm{NaCl}$ salt, which has the same ion valent of the $\mathrm{IL}$, leads to anion exchange with $\mathrm{HMIMPF}_{6}$ and produces $\mathrm{HMIMCl}$, soluble in water [27]:

$$
\mathrm{HMIMPF}_{6}+\mathrm{NaCl} \rightleftarrows \mathrm{HMIMCl}+\mathrm{PF}_{6}{ }^{-}+\mathrm{Na}^{+}
$$

This reaction, in turn, increases the IL solubility in aqueous phase and further leads the acetone extraction to diminish [8,27,28].

Adding 0.05 and 0.10 mass fraction of $\mathrm{Na}_{2} \mathrm{SO}_{4}$ provides an average enhancement of about $51.84 \%$ and $92.37 \%$ in acetone distribution coefficient, respectively. The higher activity of sufate anion gives higher salting-out effect, compared with chlorine anion (Hafmister series), under similar conditions. With the aim of comparison, under a typical acetone concentration of $w_{21}=$ 0.13, the range of $D_{2}$ is demonstrated in Fig. 6 for different cases.

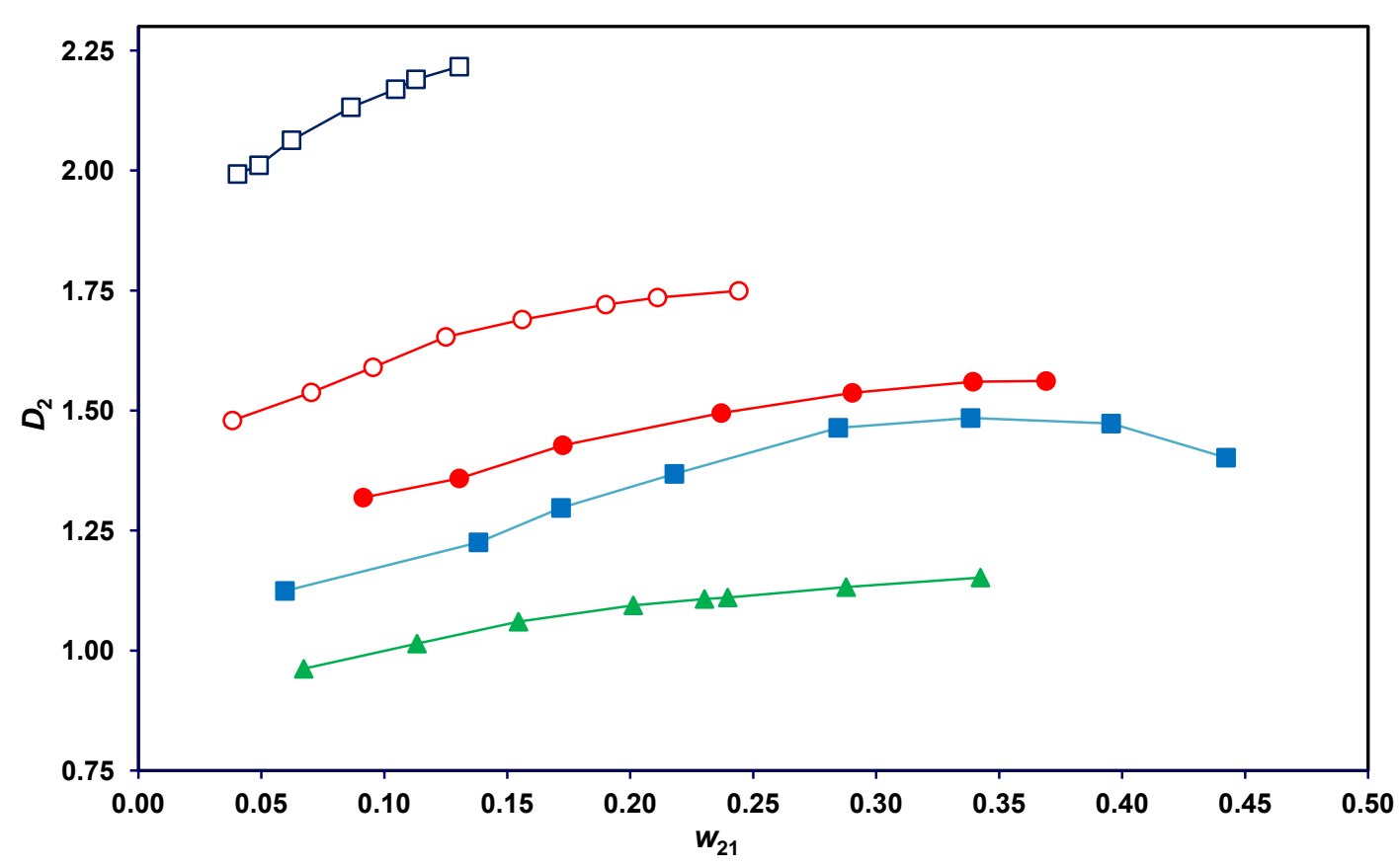


Fig. 5. Variation of acetone distribution coefficient with its concentration in aqueous phase: salt-free $(\boldsymbol{\Delta}), 0.05(\bullet)$ and $0.10(-)$ mass fractions of $\mathrm{NaCl}$, and $0.05(\circ)$ and $0.10(\square)$ mass fractions of $\mathrm{Na}_{2} \mathrm{SO}_{4}$.

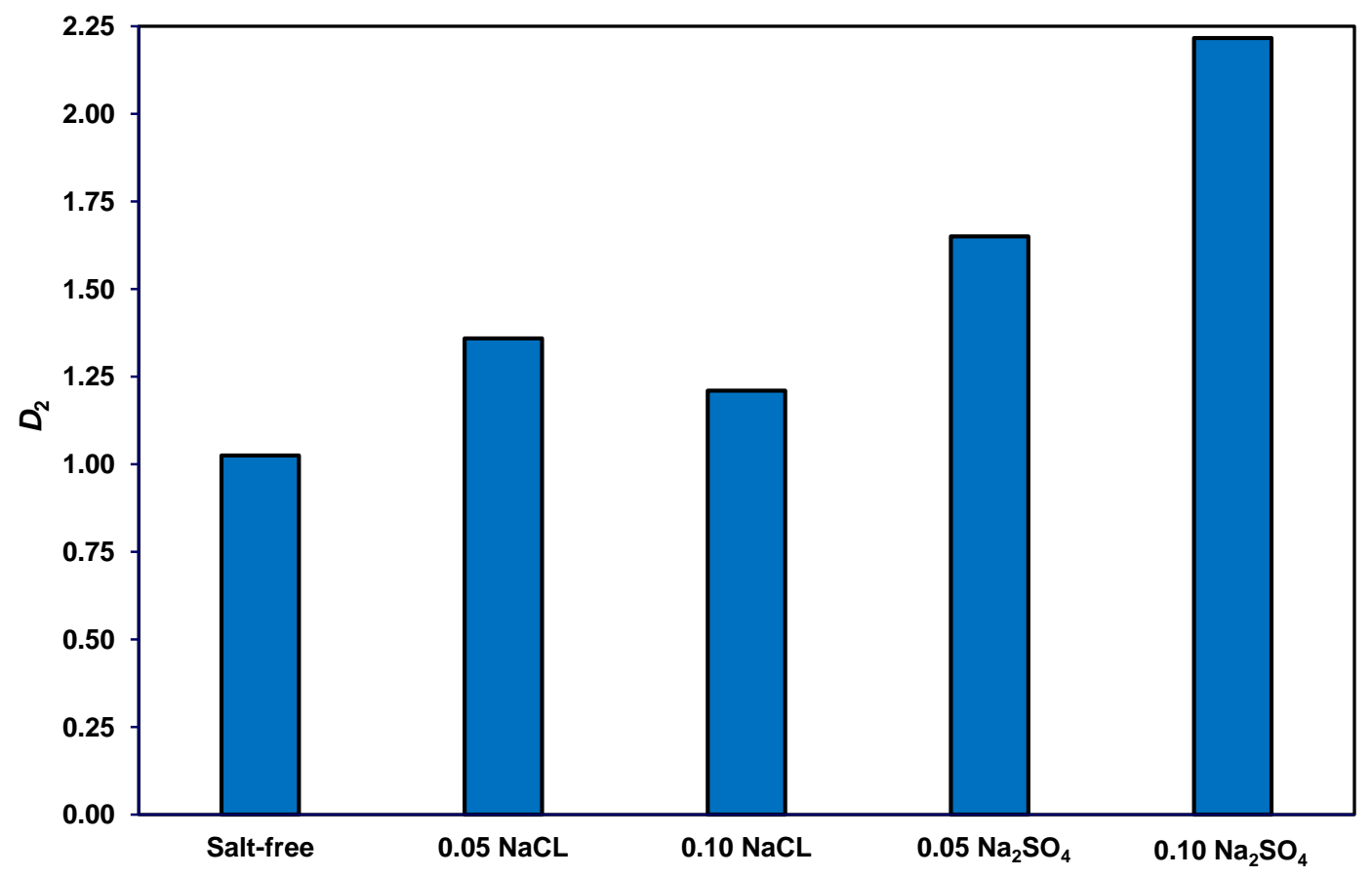

Fig. 6. Comparison of acetone distribution coefficent in different cases and for a typical concentration of $w_{21}=0.13$.

On the other hand, the influence of salts on the water distribution coefficient is shown in Fig. 7. Adding $\mathrm{NaCl}$ salt leads a decrease in $D_{1}$, while $\mathrm{Na}_{2} \mathrm{SO}_{4}$ improves this distribution coefficient. The higher $D_{1}$ value with $\mathrm{Na}_{2} \mathrm{SO}_{4}$ can be interpreted with the more solubility of water in IL phase, provided by high concentration of acetone which in-turn is accompanied with more water withdraw into IL phase. The contrary effect of $\mathrm{NaCl}$ on $D_{1}$ can be attritbuted to its high molar concentration in aqueous phase, leading to high level of its ions hydration and therefore lower water transfer into IL phase. Of course, as is appeared in the figure, the influence of anion exchange, appeared at high salt mass fraction of 0.10 , gives a lower effect in this regard compared with its mass fraction of 0.05 . 


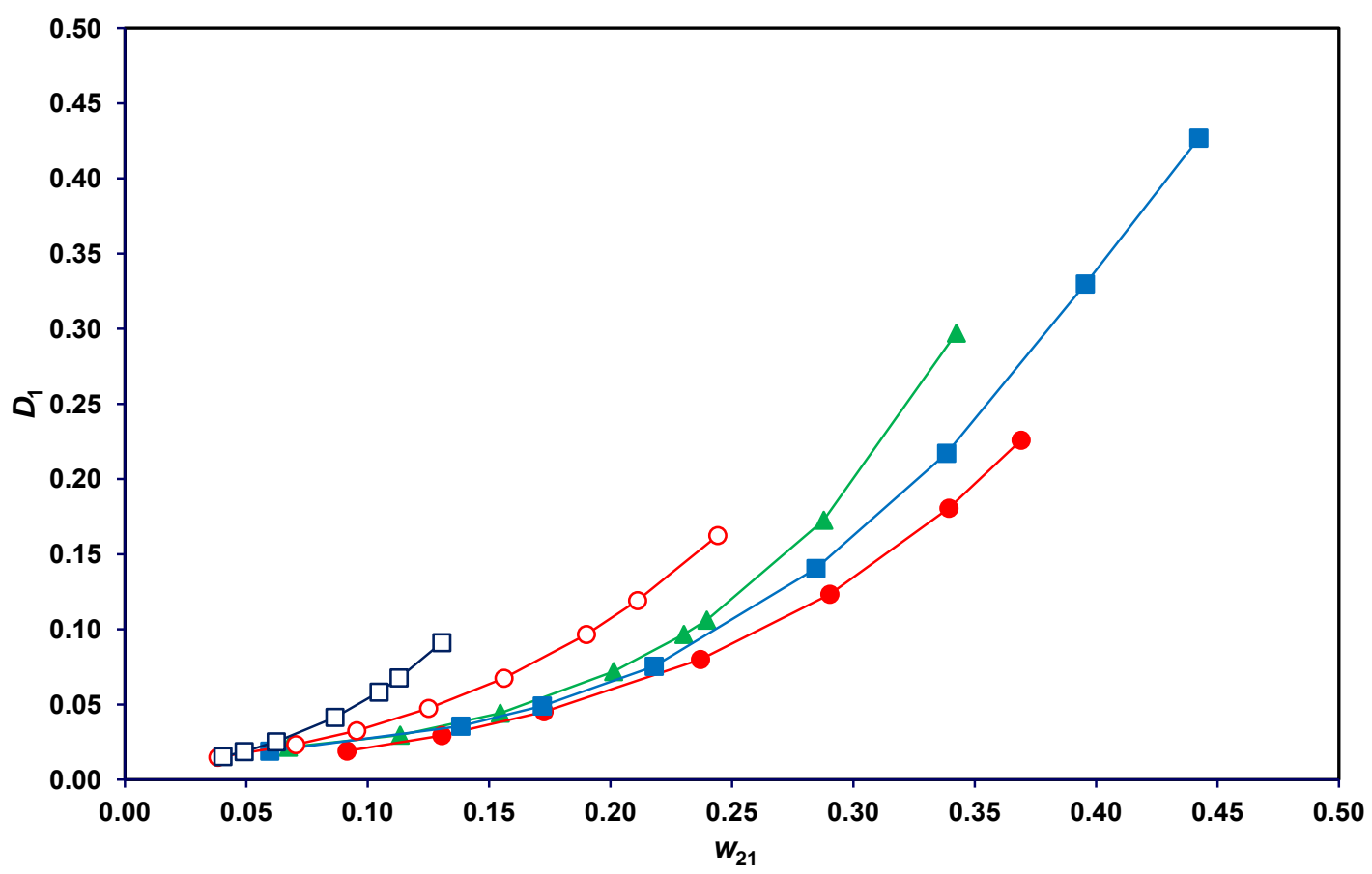

Fig. 7. Variation of water distribution coefficient with acetone concentration in aqueous phase: salt-free $(\mathbf{\Delta}), 0.05$ $(\bullet)$ and $0.10(\bullet)$ mass fractions of $\mathrm{NaCl}$, and $0.05(\circ)$ and $0.10(\square)$ mass fractions of $\mathrm{Na}_{2} \mathrm{SO}_{4}$.

Fig. 8 shows variation of separation factor with acetone concentration, either in salt free or in the presence of salts. Separation factor generally decreases with solute concentration due to presence of more water in the IL phase. However, adding salts provides a significant enhancement in separation factor as a consequence of acetone and water distribution factors variations and hence more effective of the earlier. The average enhancement in separation factor reaches to $55.62 \%$ with 0.05 and $33.13 \%$ with 0.10 mass fraction of $\mathrm{NaCl}$. Accordingly, much higher separation factor of $122.98 \%$ and $191.62 \%$ are achieved with $\mathrm{Na}_{2} \mathrm{SO}_{4}$. It is while water distribution coefficient was also higher with the latter salt (Fig 7). 


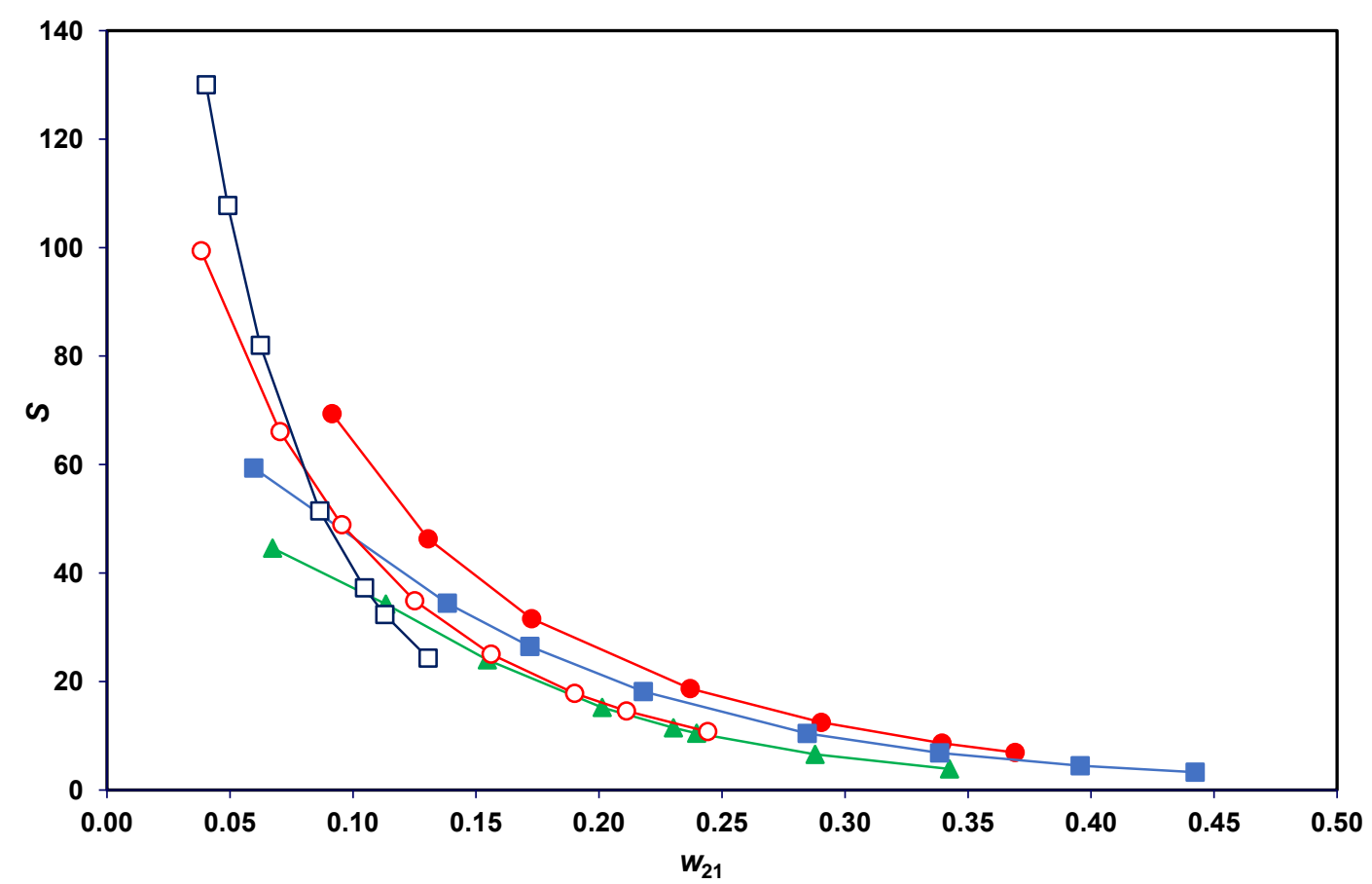

Fig. 8. Variation of acetone separation factor with its concentration in aqueous phase: salt-free $(\boldsymbol{\Delta}), 0.05(\bullet)$ and $0.10(\square)$ mass fractions of $\mathrm{NaCl}$, and $0.05(\circ)$ and $0.10(\square)$ mass fractions of $\mathrm{Na}_{2} \mathrm{SO}_{4}$.

Figs. 9 and 10 indicate that a greater binary region (shaded area) is achieved by the salt addition due to the less tendency of water-IL miscibility. Of course solubility of the IL in water is to some extent less than water in the IL. It has to be noted that results presented in these figures are based on salt-free composition data. Dupont et al. [8] proposed a "liquid-precipitate" model to rationalize the effect of inorganic salts on the solubility of any hydrophobic IL. Based on this model, charge-neutralizing ion pairs can be formed between the IL ions and salt counterions. Salt ions (like ones used here) which are more efficient in neutralizing the IL ions charge than water molecules, decrease the IL solubility in water. Surely, the effect of salts on the solubility of ILs follows the charge-density series (the Hafmester series) because a higher charge density results in stronger charge-neutralizing ion pairs [8]. 


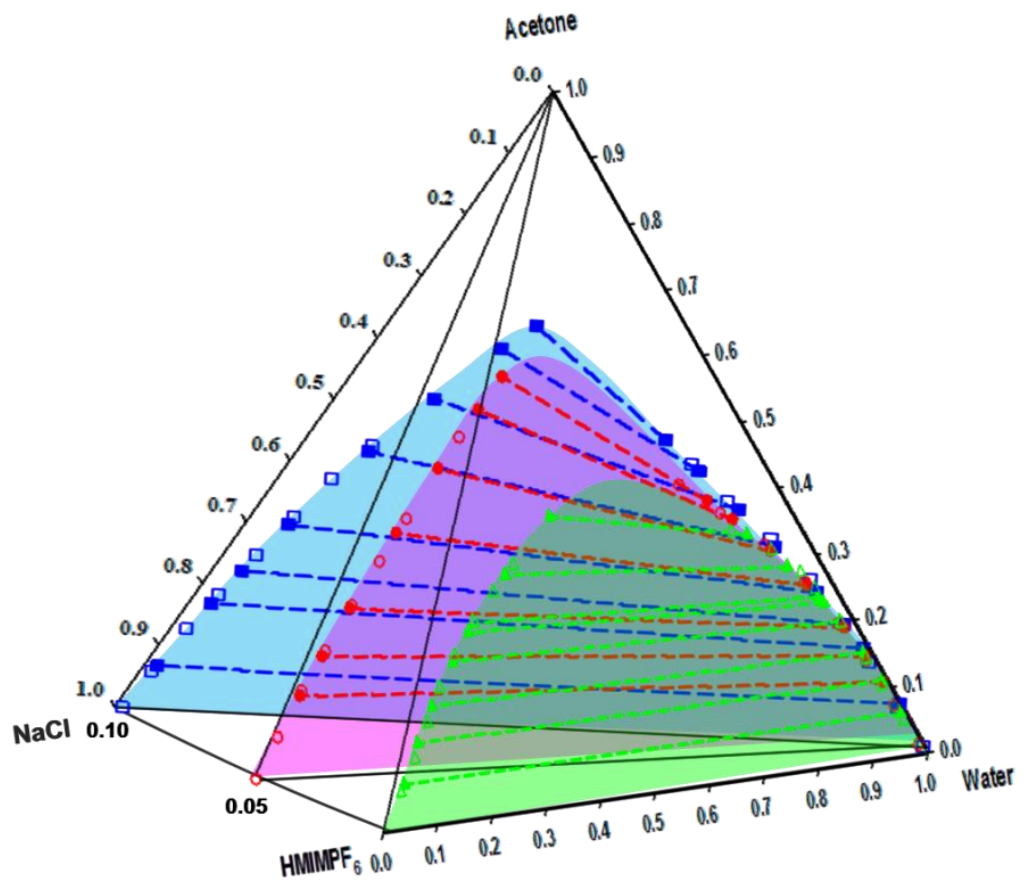

Fig. 9. Binary regions, tie-line $(\boldsymbol{\Lambda}, \bullet$ and $\boldsymbol{\square})$ and solubility data $(\Delta, \circ$ and $\square)$ for salt-free, 0.05 and 0.10 mass fractions of $\mathrm{NaCl}$.

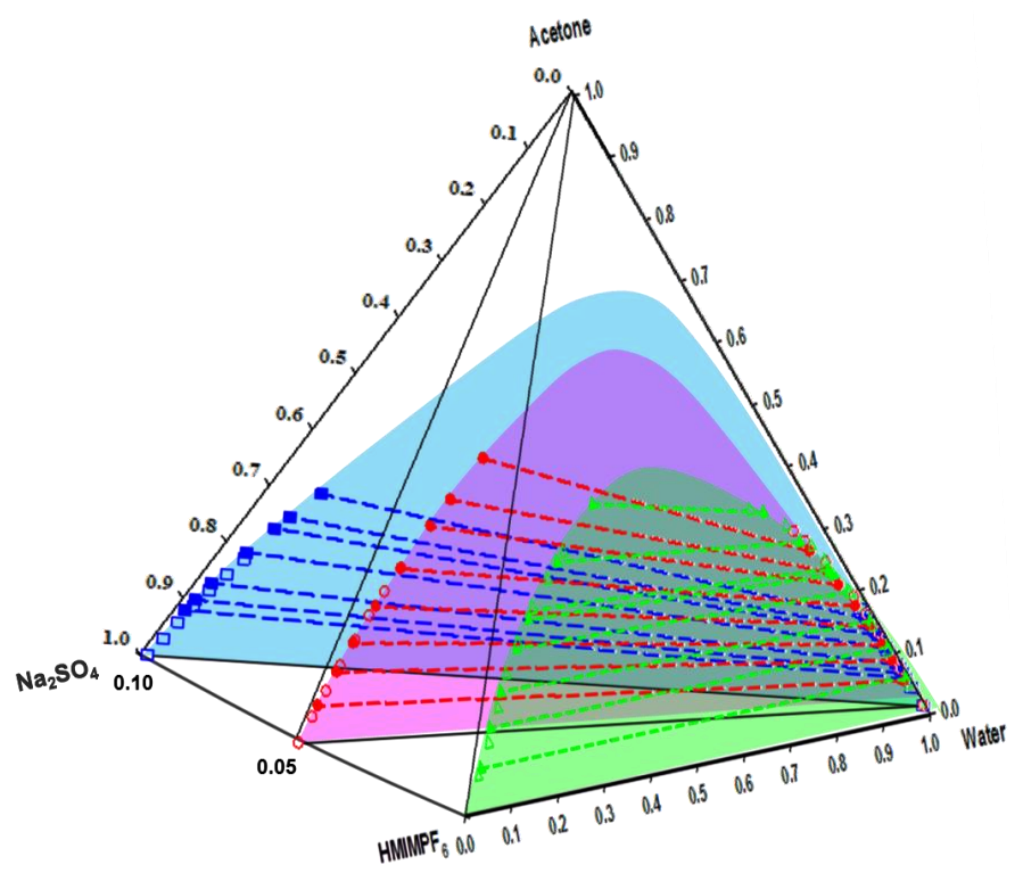

Fig. 10. Binary regions, tie-line $(\boldsymbol{\Lambda}, \bullet$ and $\boldsymbol{\square})$ and solubility data $(\Delta, \circ$ and $\square)$ for salt-free, 0.05 and 0.10 mass fractions of $\mathrm{Na}_{2} \mathrm{SO}_{4}$. 
The consistency of provided data for salt solutions, is frequently examined with the improved version of Eisen-Joffe equation $[29,30]$. The extended equation is given as:

$$
\log \left(\frac{w_{23}}{w_{33}}\right)=\left(a^{\prime}+b^{\prime} w_{s}\right)+\left(c^{\prime}+d^{\prime} w_{s}\right) \log \left(\frac{w_{21}}{w_{11}}\right)
$$

where $w_{\mathrm{s}}$ represents the mass fraction of salt in the initial salt solution. The letters $a^{\prime}, b^{\prime}, c^{\prime}$ and $d^{\prime}$ are parameters of the Eisen-Joffe equation, which depend upon the nature of the system components, including that of the salt and temperature. Further, $b$ ' and $d$ ' are relevant to the salt concentration, while $a^{\prime}$ and $c^{\prime}$ are not. The obtained parameters of the improved Eisen-Joffe equation are listed in Table 4 . The coefficient of determination $\left(R^{2}\right)$ close to unity indicates the degree of the consistency of the data.

\section{Table 4}

Parameters of the Eisen-Joffe equation for water (1) + acetone (2) + IL (3) + salt (4) at different salt concentrations.

\begin{tabular}{lccccc}
\hline$w_{\mathrm{s}}$ & $a^{\prime}$ & $b^{\prime}$ & $c^{\prime}$ & $d^{\prime}$ & $R^{2}$ \\
\hline Salt-free & 0.1892 & - & 1.1914 & - & 0.9987 \\
$0.05 \mathrm{NaCl}$ & & 4.7560 & & 3.0522 & 0.9980 \\
$0.10 \mathrm{NaCl}$ & & 4.3420 & & 14.3030 & 0.9914 \\
$0.05 \mathrm{Na}_{2} \mathrm{SO}_{4}$ & & 10.0041 & & 25.4841 & 0.9962 \\
$0.10 \mathrm{Na}_{2} \mathrm{SO}_{4}$ & & 6.3583 & & 12.7550 & 0.9984 \\
\hline
\end{tabular}

\subsection{LLE correlation}

There are many papers in which LLE data for ternary systems containing salts have been correlated with Non Random Two Liquid (NRTL) as well as UNIversal QUAsi Chemical (UNIQUAC) models [31-33], which were utilized in this work. The basic relationships in these models, for every component $i$ in coexistent liquid phases at equilibrium, are as following:

$$
\begin{aligned}
& x_{i}^{I} \gamma_{i}^{I}=x_{i}^{I I} \gamma_{i}^{I I} \\
& \sum x_{i}^{I}=\sum x_{i}^{I I}=1
\end{aligned}
$$

where $x_{i}^{I}, x_{i}^{I I}, \gamma_{i}^{I}$ and $\gamma_{i}^{I I}$ are the mole fraction and activity coefficient of component $i$ in phases $I$ and $I I$, respectively. 
The model parameters of the NRTL and UNIQUAC equations were distinguished via data regression using Aspen Plus (V. 7.1) simulator. This software uses an objective function called "maximum likelihood" and an algorithm called Britt-Luecke to correlate model parameters [34].

In the NRTL model, the activity coefficient for component $i$ is represented as [35]:

$$
\ln \gamma_{i}=\frac{\sum_{j} x_{j} \tau_{j i} G_{j i}}{\sum_{k} x_{k} G_{k i}}+\sum_{j} \frac{x_{j} G_{i j}}{\sum_{k} x_{k} G_{k j}}\left(\tau_{i j}-\frac{\sum_{v} x_{v} \tau_{v j} G_{v j}}{\sum_{k} x_{k} G_{k j}}\right)
$$

where $x$ is the mole fraction, and $G$ is binary parameters for NRTL model, while $i, j, k$ and $v$ are indices, each of them for all of the components. Also, the binary interactions were calculated by $[34,36]:$

$$
\begin{aligned}
& \tau_{i j}=a_{i j}+\frac{b_{i j}}{T}+e_{i j} \ln T+f_{i j} T \\
& \alpha_{i j}=\alpha_{j i}=c_{i j}+d_{i j}(T-273.2) \\
& G_{i j}=\exp \left(-\alpha_{i j} \tau_{i j}\right)
\end{aligned}
$$

where $\tau_{i j}$ and $G_{i j}$ are NRTL parameters which are determined via the parameters $a_{i j}, b_{i j}(\mathrm{~K}), c_{i j}$, $d_{i j}$ and $e_{i j}$.

The other well known UNIQUAC equation for the liquid phase activity coefficient is illustrated as [37]:

$$
\ln \gamma_{i}=\ln \gamma_{i}^{C}(\text { combinatorial })+\ln \gamma_{i}^{R}(\text { residual })
$$

where the combinatorial and residual terms of the activity coefficient are relevant to the difference in shape and energy of the molecules, respectively. These terms are given as:

$$
\begin{aligned}
& \ln \gamma_{i}^{C}=\ln \left(\frac{\Phi_{i}}{x_{i}}\right)+\frac{z}{2} q_{i} \ln \left(\frac{\theta_{i}}{\Phi_{i}}\right)+l_{i}-\frac{\Phi_{i}}{x_{i}} \sum_{j=1}^{t} x_{j} l_{j} \\
& \ln \gamma_{i}^{R}=q_{i}\left[1-\ln \left(\sum_{j=1}^{t} \theta_{j} \tau_{j i}\right)-\sum_{j=1}^{t}\left(\frac{\theta_{j} \tau_{i j}}{\sum_{k=1}^{t} \theta_{k} \tau_{k j}}\right)\right]
\end{aligned}
$$

where $i, j$ and $k$ are indices, $t$ is the number of components, $z$ is the coordination number and the UNIQUAC parameter $l_{i}$ is: 


$$
l_{i}=\frac{z}{2}\left(r_{i}-q_{i}\right)-\left(r_{i}-1\right)
$$

and $\tau_{i j}$ is the adjustable parameter in this equation, presented by [36]:

$$
\tau_{i j}=\exp \left(-\frac{\Delta u_{i j}}{R T}\right)=a_{i j}+\frac{b_{i j}}{T}+c_{i j} \ln T+d_{i j} T
$$

where $\Delta u_{i j}$ is the interaction energy parameters and also $a_{i j}, b_{i j}, c_{i j}$ and $d_{i j}$ are UNIQUAC coefficients of the equations for binary interaction parameters. The parameters $\Phi_{i}$ (segment fraction) and $\theta_{i}$ (area fraction) are indicated as the following equations:

$$
\begin{gathered}
\Phi_{i}=\frac{x_{i} r_{i}}{\sum_{j=1}^{c} x_{j} r_{j}} \\
\theta_{i}=\frac{x_{i} q_{i}}{\sum_{j=1}^{c} x_{j} q_{j}}
\end{gathered}
$$

The UNIQUAC structural parameters $r$ (the number of segments per molecules) and $q$ (the relative surface area per molecules) have been calculated from the number of molecular groups and the individual values of the van der Waals volume and area of the molecule using the Bondi method [38,39]. The detailed description of the meaning and value of parameters have been represented in the literature [40] and our previous work [16]. UNIQUAC structural parameters $r$ and $q$ for the used ionic liquid, $\mathrm{HMIMPF}_{6}$, has already been determined by Santiago et al. [41] as 9.681 and 7.845, respectively.

Listed in Tables 5 and 6 are the binary interaction coefficients in the presence of salts of $\mathrm{NaCl}$ and $\mathrm{Na}_{2} \mathrm{SO}_{4}$ that were obtained by Aspen Plus based on the NRTL and UNIQUAC models. Comparisons between experimental and correlated composition data are shown in Figs. 11 and 12 at temperature of $298.2 \mathrm{~K}$. As is obvious, correlating with both of the used models exhibits satisfactory agreement, consistent for all solute concentrations. 


\section{Table 5}

NRTL and UNIQUAC binary interaction coefficients for water (1) + acetone (2) $+\mathrm{HMIMPF}_{6}(3)+\mathrm{NaCl}(4)$ system.

\begin{tabular}{lrrrrrr}
\hline Component $i$ & 1 & 1 & 1 & 2 & 2 & \multicolumn{1}{c}{4} \\
Component $j$ & \multicolumn{1}{c}{2} & \multicolumn{1}{c}{3} & \multicolumn{1}{c}{4} & \multicolumn{1}{c}{3} & \multicolumn{1}{c}{4} & \multicolumn{1}{c}{3} \\
\hline NRTL & & & & & & \\
$a_{i j}$ & 0.05 & 0.00 & 0.00 & 0.00 & 0.00 & 0.00 \\
$a_{j i}$ & 6.40 & 0.00 & 0.00 & 0.00 & 0.00 & 0.00 \\
$b_{i j}$ & 693.96 & -3090.19 & 3255.97 & -2291.85 & 200.53 & 2147.26 \\
$b_{j i}$ & 259.34 & 267.90 & 532.88 & 501.73 & -27.51 & -1796.44 \\
$c_{i j}$ & 0.30 & 0.30 & 0.30 & 0.30 & 0.30 & 0.30 \\
UNIQUAC & & & & & & \\
$a_{i j}$ & -4.83 & 0.00 & 0.00 & 0.00 & 0.00 & 0.00 \\
$a_{j i}$ & 8.61 & 0.00 & 0.00 & 0.00 & 0.00 & 0.00 \\
$b i j$ & -1866.63 & -4311.31 & -109.23 & -4353.33 & 243.23 & -2948.37 \\
$b j i$ & -7075.03 & 10000.00 & -7589.97 & 1125.20 & -3556.00 & -245.84 \\
\hline
\end{tabular}

${ }^{*}$ AAD and BIAS values for NRTL model are 0.13868 and 0.01701 , and for UNIQUAC model, 0.69902 and 0.03667 , respectively.

\section{Table 6}

NRTL and UNIQUAC binary interaction coefficients for water (1) + acetone (2) + $\mathrm{HMIMPF}_{6}(3)+\mathrm{Na}_{2} \mathrm{SO}_{4}(4)$ system. $^{*}$

\begin{tabular}{lrrrrrr}
\hline Component $i$ & 1 & 1 & 1 & 2 & 2 & \multicolumn{1}{c}{4} \\
Component $j$ & \multicolumn{1}{c}{2} & \multicolumn{1}{c}{3} & \multicolumn{1}{c}{4} & \multicolumn{1}{c}{3} & \multicolumn{1}{c}{4} & \multicolumn{1}{c}{3} \\
\hline NRTL & & & & & & \\
$a_{i j}$ & 0.05 & 0.00 & 0.00 & 0.00 & 0.00 & 0.00 \\
$a_{j i}$ & 6.40 & 0.00 & 0.00 & 0.00 & 0.00 & 0.00 \\
$b_{i j}$ & -305.05 & -926.47 & 2155.06 & 213.67 & -221.71 & 3430.69 \\
$b_{j i}$ & 3637.84 & -683.98 & 634.90 & 575.15 & -1449.00 & -1335.15 \\
$c_{i j}$ & 0.30 & 0.30 & 0.30 & 0.30 & 0.30 & 0.30 \\
UNIQUAC & & & & & & \\
$a_{i j}$ & -4.83 & 0.00 & 0.00 & 0.00 & 0.00 & 0.00 \\
$a_{j i}$ & 8.61 & 0.00 & 0.00 & 0.00 & 0.00 & 0.00 \\
$b i j$ & 1585.64 & -210.42 & -1790.39 & -2062.23 & -217.26 & 1348.04 \\
$b j i$ & -6469.86 & 9734.32 & -5006.17 & -1289.67 & 262.68 & 658.60 \\
\hline
\end{tabular}

*AAD and BIAS values for NRTL model are 0.15234 and -0.07595 , and for UNIQUAC model, 0.18044 and -0.05948 , respectively. 


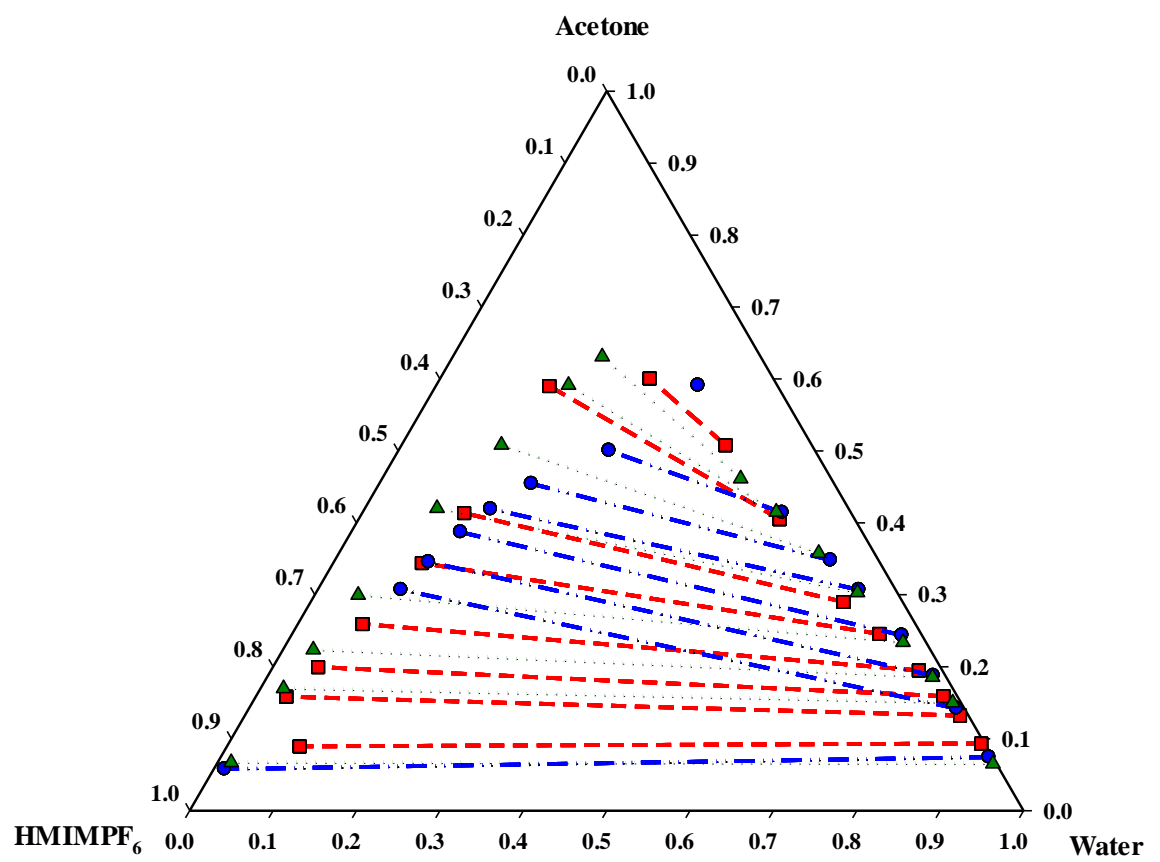

Fig. 11. Comparison between experimental tie lines (dotted line and $\boldsymbol{\Delta}$ symbol), NRTL tie lines (dashed lines and symbol), and UNIQUAC tie lines (dash-dot-dot lines and $\bullet$ symbol) with 0.10 mass fraction of $\mathrm{NaCl}$ at $298.2 \mathrm{~K}$.

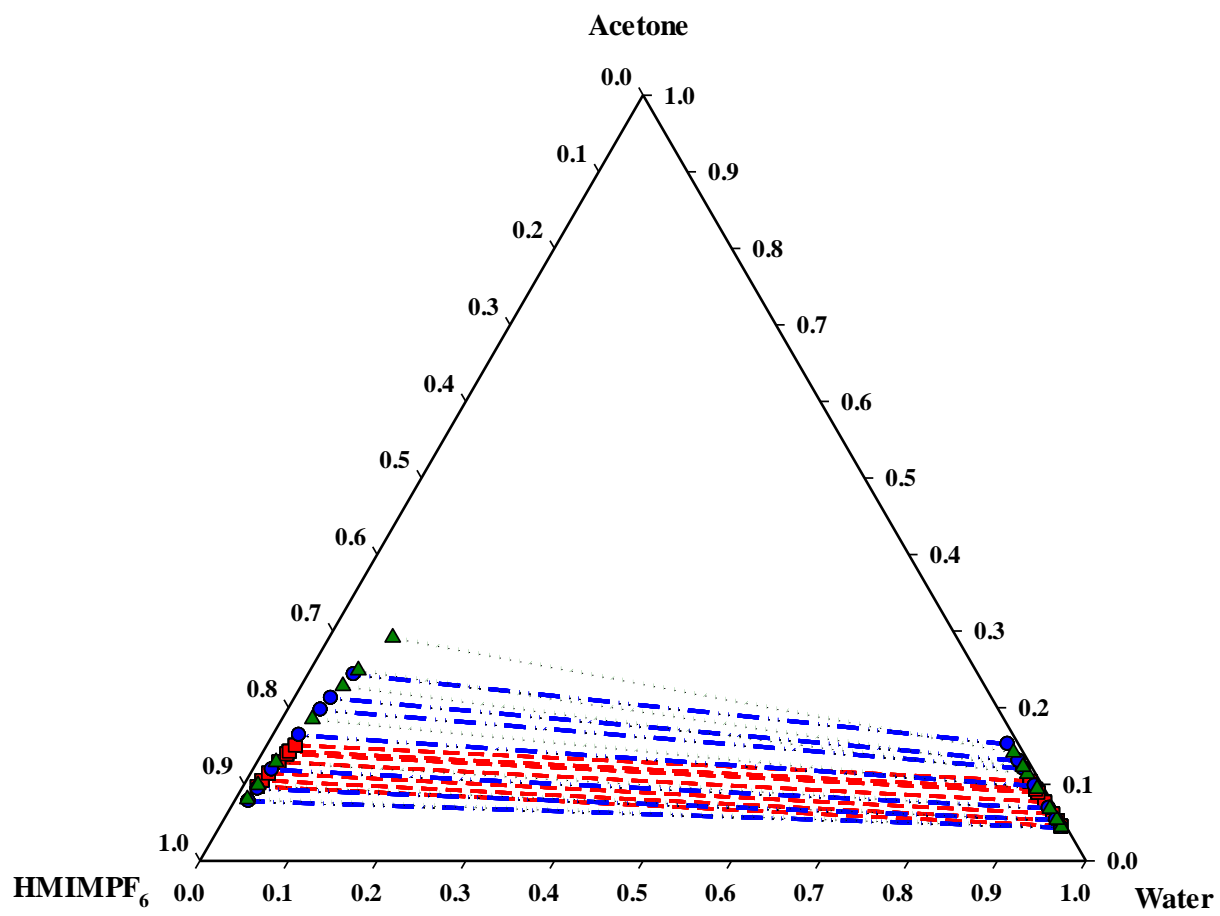

Fig. 12. Comparison between experimental tie lines (dotted line and $\boldsymbol{\Delta}$ symbol), NRTL tie lines (dashed lines and $\boldsymbol{\bullet}$ symbol), and UNIQUAC tie lines (dash-dot-dot lines and • symbol) with 0.10 mass fraction of $\mathrm{Na}_{2} \mathrm{SO}_{4}$ at $298.2 \mathrm{~K}$. 
To indicate the capability of the used models, the root mean square deviation (RMSD) between experimental and calculated data was obtained from:

$$
\mathrm{RMSD}=\sqrt{\frac{\sum_{i} \sum_{m} \sum_{n}\left(w_{i m n}^{\text {exp }}-w_{i m n}^{c a l}\right)^{2}}{6 N}}
$$

where $w_{i m n}^{\text {exp }}$ and $w_{i m n}^{\text {cal }}$ are experimental and calculated mass fractions of components $i=1,2,3,4$ in phases, $m=I, I I$ and on tie lines $n=1,2, \ldots, N$.

In the presence of $\mathrm{NaCl}$ and $\mathrm{Na}_{2} \mathrm{SO}_{4}$ salts, the RMSD values based on NRTL model were 0.0346 and 0.0634 and for UNIQUAC model 0.1093 and 0.0328 , respectively. These reasonable errors, as well as the corresponding maximum errors of $0.0953,0.2479,0.2138$ and 0.1235 , indicate that the NRTL and UNIQUAC models can satisfactorily reproduce the experimental data.

\section{Conclusions}

Considering the naturally occurring sodium salts in water sources, LLE for the quaternary systems of (water + acetone + 1-Hexyl-3-methylimidazolium hexafluorophosphate ionic liquid + $\mathrm{NaCl}$ or $\mathrm{Na}_{2} \mathrm{SO}_{4}$ ) was investigated at conventional temperature of $298.2 \mathrm{~K}$ and ambient pressure. The $\mathrm{Na}_{2} \mathrm{SO}_{4}$ salt exhibits a stronger favorite salting-out for acetone and with no anion exchange with the ionic liquid. According to results, the presence of used salts with concentrations of 0.05 and 0.10 mass fraction in water source causes enhancements in average solute distribution coefficient within (21.67 to 35.54$) \%$ with $\mathrm{NaCl}$ and (51.84 to 92.37)\% with $\mathrm{Na}_{2} \mathrm{SO}_{4}$. The problem of salt precepitation, coincident with high acetone concentrations, gives a limitaion in

utilizing higher mass fractions of salts. The experimental tie-lines agrees well with the modified Eisen-Joffe equation, indicating the consistency of data.

The NRTL and UNIQUAC models were employed to reproduce the experimental LLE data. As can be concluded from the very low root mean square deviation values, both of them can satisfactorily be used to predict the LLE of the systems. The provided data can be utilized in design and simulation of liquid-liquid extraction process when dealing with salty water. 


\section{Acknowledgement}

The authors wish to acknowledge Iran National Science Foundation (INSF) for financial support of this work. The Bu-Ali Sina University authorities are also acknowledged.

\section{References}

[1] Q. Ren, Q. Yang, Y. Yan, H. Xing, Z. Bao, B. Su, Y. Yang, Ionic Liquid-Mediated Liquid-Liquid Extraction, in: S. Handy (Ed.), Applications of Ionic Liquids in Science and Technology, (Chap. 16) publishing in Tech., USA, 2011, pp. 345-364.

[2] S. Shahriari, C.M. Neves, M.G. Freire, J.O.A. Coutinho, Role of the Hofmeister series in the formation of ionic-liquid-based aqueous biphasic systems, J. Phys. Chem. B 116 (2012) 7252-7258.

[3] J.F. Brennecke, E.J. Maginn, Ionic liquids: innovative fluids for chemical processing, AIChE J. 47 (2001) 2384-2389.

[4] S.H. Ha, N.L. Mai, Y.-M. Koo, Butanol recovery from aqueous solution into ionic liquids by liquid-liquid extraction, Process Biochem. 45 (2010) 1899-1903.

[5] A. Chapeaux, L.D. Simoni, T.S. Ronan, M.A. Stadtherr, J.F. Brennecke, Extraction of alcohols from water with 1-hexyl-3-methylimidazolium bis (trifluoromethylsulfonyl) imide, Green Chem. 10 (2008) 1301-1306.

[6] V. Najdanovic-Visak, L.P. Rebelo, M.N. da Ponte, Liquid-liquid behaviour of ionic liquid-1-butanol-water and high pressure $\mathrm{CO}_{2}$-induced phase changes, Green Chem. 7 (2005) 443-450.

[7] Berthod, S. Carda-Broch, A new class of solvents for CCC: the room temperature ionic liquids, , J. Liq. Chrom. Rel. Technol. 26 (2003) 1493-1508.

[8] D. Dupont, D. Depuydt, K. Binnemans, Overview of the effect of salts on biphasic ionic liquid/water solvent extraction systems: Anion exchange, mutual solubility and thermomorphic properties, J. Phys. Chem. B (2015) 1532-1536.

[9] F.S. Santos, S.G. d'Ávila, M.N. Aznar, Salt effect on liquid-liquid equilibrium of water+ 1-butanol+ acetone system: Experimental determination and thermodynamic modeling, Fluid Phase Equilib. 187 (2001) 265-274. 
[10] J. Saien, M. Fattahi, M. Mozafarvandi, The impact of uni-univalent electrolytes on (water+ acetic acid+ toluene) equilibria: Representation with electrolyte-NRTL model, J. Chem. Thermodyn. 74 (2014) 238-246.

[11] A. Hasseine, A. H. Meniai, M. Korichi, Salting-out effect of single salts $\mathrm{NaCl}$ and $\mathrm{KCl}$ on the LLE of the systems (water+ toluene+ acetone), (water+ cyclohexane+ 2propanol) and (water+ xylene+ methanol), Desalination 242 (2009) 264-276.

[12] M. Govindarajan, P. Sabarathinam, Salt effect on liquid-liquid equilibrium of the methyl isobutyl ketone + acetic acid + water system at $35^{\circ} \mathrm{C}$, Fluid Phase Equilib. 108 (1995) 269-292.

[13] J. Saien, M. Norouzi, H. Dehghani, The choice of solvent and liquid-liquid equilibrium for ternary water+ 2-methylaziridine+ chloroform system: Experimental data and modeling, Fluid Phase Equilib. 338 (2013) 224-231.

[14] B.F. de Almeida, T.M. Waldrigui, T.D.C. Alves, L.H. de Oliveira, M. Aznar, Experimental and calculated liquid-liquid equilibrium data for water+ furfural+ solvents, Fluid Phase Equilib. 334 (2012) 97-105.

[15] A. delos Ríos, F. Hernández Fernández, D. Gómez, M. Rubio, G. Víllora, (Liquid+ liquid) equilibrium for ternary systems containing of an ionic liquid, n-hexane and an organic compound involved in the kinetic resolution of rac-2-pentanol, Separ. Sci. Technol. 47 (2012) 300-311.

[16] J. Saien, M. Mohammadi Sarab Badieh, M. Norouzi, S. Salehzadeh, Ionic liquid 1hexyl-3-methylimidazolium hexafluorophosphate, an efficient solvent for extraction of acetone from aqueous solutions, J. Chem. Thermodyn. 91 (2015) 404-413.

[17] T. Misek, R. Berger, J. Schöter, Standard test systems for liquid extraction, Institution of Chemical Engineers, EFCE Pub. Ser. 46 (1985).

[18] A. Pereiro, E. Tojo, A. Rodriguez, J. Canosa, J. Tojo, Properties of ionic liquid HMIMPF $_{6}$ with carbonates, ketones and alkyl acetates, J. Chem. Thermodyn. 38 (2006) $651-661$.

[19] W.M. Haynes, CRC Handbook of Chemistry and Physics, CRC press, 2014.

[20] Abbe Refractometer Instruction Manual, http://www.kruess.com/laboratory/products/ refractometers/abbe-refractometers. 
[21] M. Pai, K.M. Rao, Salt-Effect on liquid-liquid equilibria in the ethyl acetate-ethyl alcohol-water system, J. Chem. Eng. Data 11 (1966) 353-356.

[22] M.F. Hegazi, A.B. Salem, Ternary data for the acetic acid-water-mesityl oxide system, J. Chem. Tech. Biotechnol. 33 (1983) 145-150.

[23] H. Ohno, Physical Properties of Ionic Liquids for Electrochemical Applications, in: F. Endres, A. P. Abbott, and D.R. MacFarlane (Eds), Electrodeposition from ionic liquids, 2008, pp. 47-82.

[24] D. Laiadi, A. Hasseine, A. Merzougui, Homotopy method to predict liquid-liquid equilibria for ternary mixtures of (water+ carboxylic acid+ organic solvent), Fluid Phase Equilibria, 313 (2012) 114-120.

[25] N. Deenadayalu, K.C. Ngcongo, T.M. Letcher, D. Ramjugernath, Liquid-liquid equilibria for ternary mixtures (an ionic liquid+ benzene+ heptane or hexadecane) at $\mathrm{T}=$ 298.2 K and atmospheric pressure, J. Chem. Eng. Data 51 (2006) 988-991.

[26] H.N. Solimo, Liquid-liquid equilibria for the water+ ethanol+ 2-ethyl-1-hexanol ternary system at several temperatures, Can. J. Chem. 68 (1990) 1532-1536.

[27] Q. Zhou, H. Bai, G. Xie, J. Xiao, Temperature-controlled ionic liquid dispersive liquid phase micro-extraction, J. Chromatogr. A 1177 (2008) 43-49.

[28] A. Gure, F.J. Lara, A.M. García-Campaña, N. Megersa, M. del Olmo-Iruela, Vortexassisted ionic liquid dispersive liquid-liquid microextraction for the determination of sulfonylurea herbicides in wine samples by capillary high-performance liquid chromatography, Food Chem. 170 (2015) 348-353.

[29] E.O. Eisen, J. Joffe, Salt effects in liquid-liquid equilibria, J. Chem. Eng. Data 11 (1966) 480-484.

[30] X. Chen, X. Gao, H. Zheng, S. Zhao, Salting effect on the liquid-liquid equilibrium for the ternary system water+ methanol+ methyl acetate at 283.15 K, Fluid Phase Equilib. 313 (2012) 102-106.

[31] S. Mo, J. Li, Y. Jin, J. Luo, X. Jia, X. Chen, Liquid-liquid equilibrium of 1-butanol+ water+ tri-n-butyl phosphate+ ammonium chloride system, Fluid Phase Equilib. 378 (2014) 73-77. 
[32] M.K. Khuntia, Salt effect on liquid liquid equilibrium for ternary system water+ 1propanol+ ethyl acetate, MSc Thesis in, National Institute of Technology Rourkela, 2006.

[33] M.A. Pereira, M. Aznar, Salt effect on (liquid+ liquid) equilibrium of (water+tertbutanol+ 1-butanol) system: Experimental data and correlation, J. Chem. Thermodyn. 38 (2006) 84-89.

[34] J. Saien, M. Norouzi, Salting-out effect of $\mathrm{NaCl}$ and $\mathrm{KCl}$ on the liquid-liquid equilibrium of water+ 2-methylpropanoic acid+(1-methylethyl)-benzene System at several temperatures, J. Chem. Eng. Data 56 (2011) 2892-2898.

[35] H. Renon, J.M. Prausnitz, Local compositions in thermodynamic excess functions for liquid mixtures, AIChE J. 14 (1968) 135-144.

[36] Aspen Plus 7.1 User Guide, Aspen Technology, MA, http://support. Aspentech.com, 2010.

[37] T. Anderson, J. Prausnitz, Application of the UNIQUAC equation to calculation of multicomponent phase equilibria. 1. Vapor-liquid equilibria, Ind. Eng. Chem. Process Des. Dev. 17 (1978) 552-561.

[38] A.A. Bondi, Physical properties of molecular crystals liquids, and glasses, (1968).

[39] A. Bondi, van der Waals volumes and radii, J. Phys. Chem. 68 (1964) 441-451.

[40] T. Banerjee, M.K. Singh, R.K. Sahoo, A. Khanna, Volume, surface and UNIQUAC interaction parameters for imidazolium based ionic liquids via polarizable continuum model, Fluid Phase Equilib. 234 (2005) 64-76.

[41] R.S. Santiago, G.R. Santos, M. Aznar, UNIQUAC correlation of liquid-liquid equilibrium in systems involving ionic liquids: the DFT-PCM approach. Part II, Fluid Phase Equilib. 293 (2010) 66-72. 

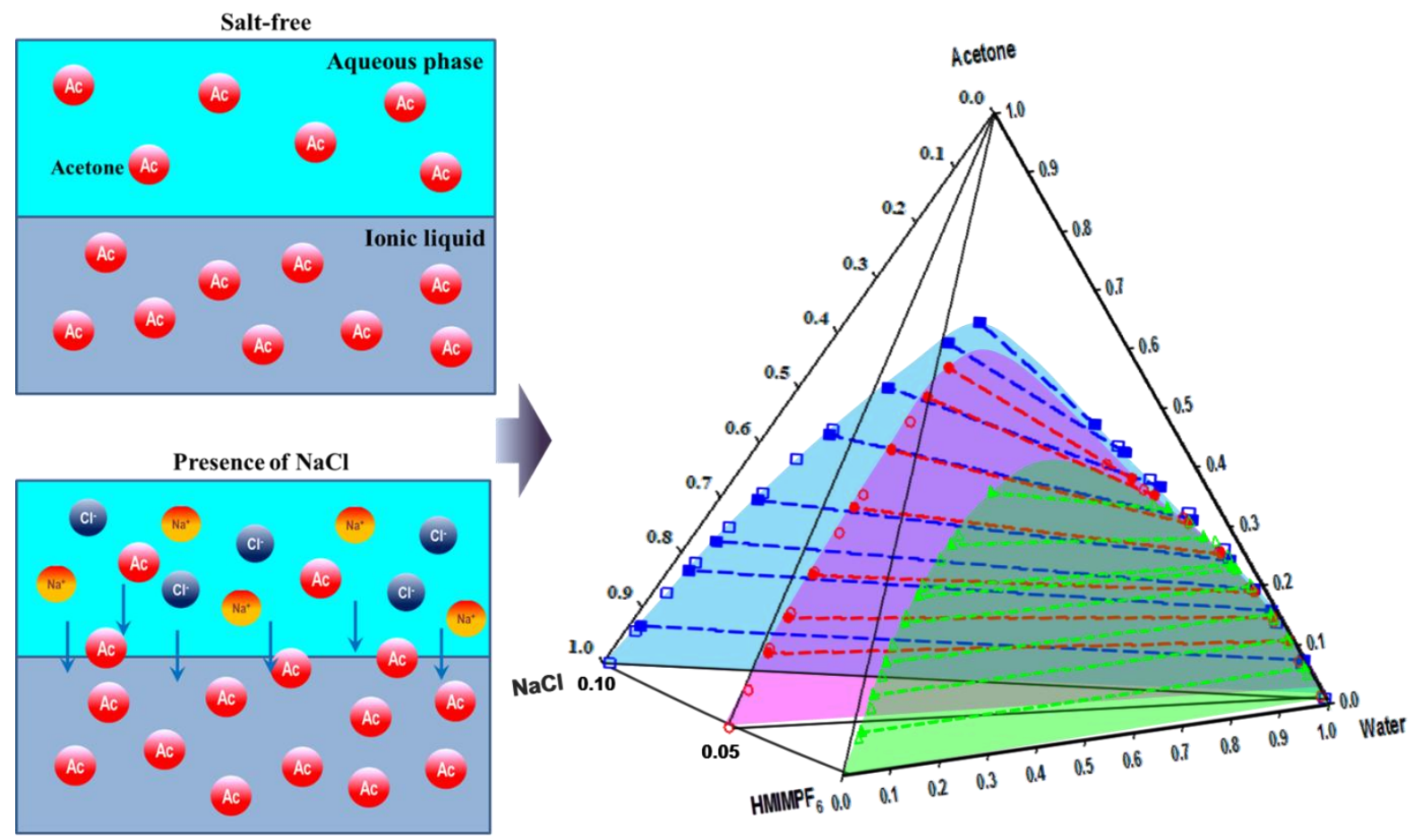

[42] 